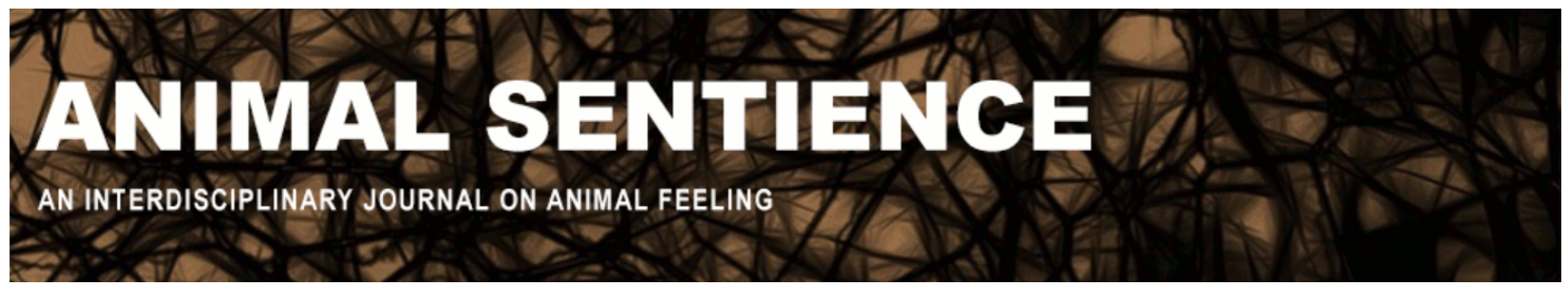

Criscione, Matthew J. and Keenan, Julian Paul (2019) Our brains make us out to be unique in ways we are not. Animal Sentience 23(38)

DOI: $10.51291 / 2377-7478.1421$

Date of submission: 2019-02-14

Date of acceptance: 2019-02-23

(c)

This article has appeared in the journal Animal

Sentience, a peer-reviewed journal on animal

cognition and feeling. It has been made open access,

free for all, by WellBeing International and deposited

in the WBI Studies Repository. For more information,

please contact

wbisr-info@wellbeingintl.org.

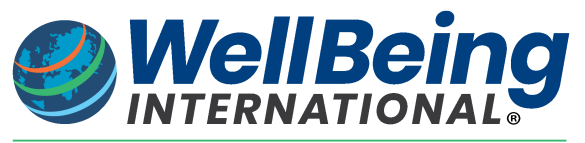

SOLUTIONS FOR PEOPLE, ANIMALS AND ENVIRONMENT 


\title{
Our brains make us out to be unique in ways we are not
}

Commentary on Chapman \& Huffman on Human Difference

\author{
Matthew J. Criscione \& Julian Paul Keenan \\ Biology and Psychology, Montclair State University, NJ
}

\begin{abstract}
Humans have long viewed themselves in a favorable light. This bias is consistent with a general pattern of self-enhancement. Neural systems in the medial prefrontal cortex underlie this way of thinking, which, even when false, may be beneficial for survival. It is hence not surprising that we often disregard contrary evidence in believing ourselves superior.
\end{abstract}

Matthew J. Criscione, member of the Cognitive Neuroimaging Laboratory at Montclair State, is pursuing a Bachelor of Science. He has published work in health physiology and self-face recognition in narcissism. Website

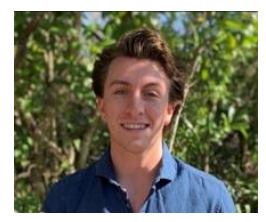

Julian Paul Keenan, Director, Cognitive Neuroimaging Laboratory, and Professor, Biology and Psychology, Montclair State University, studies the neural correlates of self-awareness. Founder of the journal Social Neuroscience and author and editor of 10 books, his current research is on the brain and self in deception. Website

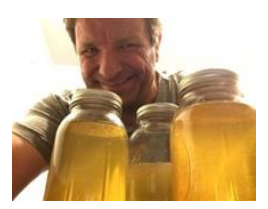

Humans have long thought of themselves as holding a privileged position. Scientific discoveries over the centuries (e.g., Copernicus) have modified this anthropocentric view, with Darwin $(1859 / 2003)$ presenting the strongest evidence that we are no more unique than any other lifeform. Although humans do have some exclusive adaptations (e.g., active teaching, fine motor skills, spoken and written language), there is little that distinguishes us from other primates or mammals at a biological level (Hayahi \& Matsuzawa, 2017). The belief that humans are a special species nevertheless exists to this day (Chapman \& Huffman, 2018). We therefore ask: "Is there a specific reason why humans consider themselves as special in light of such strong counterevidence?"

One explanation might be that our species has specific brain functions that alter our perception of reality to make us see ourselves as privileged and unique. The basis for this tendency is the medial prefrontal cortex (MPFC), a brain region that subserves first-person narratives and self-awareness. The function of this area includes ego-inflation and selfenhancement. This sense of being special changes as the MPFC develops (Alarcón, Sauder, Teoh, Forbes, \& Quevedo, 2019; Quevedo et al., 2016, 2018). Ego-protection and expansion are core parts of human development (Rodman, Powers, \& Sommerville, 2017).

Impression management is associated with MPFC activity: seeing oneself in a favorable light is in fact the baseline state (Farrow, Burgess, Wilkinson, \& Hunter, 2015). When rating ourselves compared to intimate others, we tend to see ourselves more favorably (Luber, Lou, 
Keenan, \& Lisanby, 2012). Neuroimaging shows that the MPFC is activated when participants are involved in self-enhancement (Lou \& Rosenthall, 2017). Disruption of the MPFC with transcranial magnetic stimulation decreases self-enhancement (Barrios, et al., 2008). There are similar findings regarding knowledge; participants pretend to know more than they do, and disruption of the MPFC decreases these claims (Amati, Oh, Kwan, Jordan, \& Keenan, 2010). Selfenhancement even occurs within single individuals comparing themselves to their previous self. We tend to see ourselves as smarter and wiser currently compared to the past even when data indicate this is not so (Hitchcock, Rees, \& Dalgleish, 2017).

Seeing oneself as privileged provides significant benefits. People who self-enhance have a lower risk of depression and suicide (Hitchcock, Rees, \& Dalgleish, 2017). In an extensive review of over 125,000 individuals, increased self-enhancement was found to be correlated with better personal adjustment. This finding remained significant across gender, age, and culture (Dufner, Gebauer, Sedikides, \& Denissen, 2018). It is accordingly neither surprising nor encouraging to see such beliefs holding strong today.

\section{References}

Alarcón, G., Sauder, M., Teoh, J. Y., Forbes, E. E., \& Quevedo, K. (2019). Amygdala functional connectivity during self-face processing in depressed adolescents with recent suicide attempt. Journal of the American Academy of Child and Adolescent Psychiatry, 58, 221-231.

Amati, F., Oh, H., Kwan, V. S., Jordan, K., \& Keenan, J. P. (2010). Overclaiming and the medial prefrontal cortex: A transcranial magnetic stimulation study. Cognitive Neuroscience, 1, 268276.

Barrios, V., Kwan, V. S., Ganis, G., Gorman, J., Romanowski, J., \& Keenan J. P. (2008). Elucidating the neural correlates of egoistic and moralistic self-enhancement. Consciousness and Cognition, 17, 451-456.

Chapman, C. A., \& Huffman, M. A. (2018). Why do we want to think humans are different? Animal Sentience 23(1).

Darwin, C. (2003). On the Origin of Species, 1859. London: Routledge.

Dufner, M., Gebauer, J. E., Sedikides, C., \& Denissen, J. J. A. (2018). Self-enhancement and psychological adjustment: A meta-analytic review. Personality and Social Psychology Review, 23, 48-72.

Farrow, T. F., Burgess, J., Wilkinson, I. D., \& Hunter, M. D. (2015). Neural correlates of selfdeception and impression management. Neuropsychologia, 67, 159-174.

Hayahi, M., \& Matsuzawa, T. (2017). Mother-infant interactions in captive and wild chimpanzees. Infant Behavior and Development, 48, 20-29.

Hitchcock, C., Rees, C., \& Dalgleish, T. (2017). The devil's in the detail: Accessibility of specific personal memories supports rose-tinted self-generalizations in mental health and toxic selfgeneralizations in clinical depression. Journal of Experimental Psychology: General, 146, 1286-1295.

Lou, H., C., \& Rosenthall, A. (2017). Towards a cognitive neuroscience of self-awareness. Neuroscience and Biobehavioral Reviews, 83, 765-773. 
Luber, B., Lou, H. C., Keenan, J. P., \& Lisanby, S. H. (2012). Self-enhancement processing in the default network: A single-pulse TMS study. Experimental Brain Research, 223, 177-187.

Quevedo, K., Harms, M., Sauder, M., Scott, H., Mohamed, S., Thomas, K. M., Schallmo, M. P., \& Smyda, G. (2018). The neurobiology of self face recognition among depressed adolescents. Journal of Affective Disorders, 229, 22-31.

Quevedo, K., Ng, R., Scott, H., Martin, J., Smyda, G., Keener, M., \& Oppenheimer, C. W. (2016). The neurobiology of self-face recognition in depressed adolescents with low or high suicidality. Journal of Abnormal Psychology, 125, 1185-1200.

Rodman, A. M., Powers, K. E., \& Somerville, L. H. (2017). Development of self-protective biases in response to evaluative feedback. Proceedings of the National Academy of Sciences, 114, 13158-13163. 